\title{
EGU21-5609
}

https://doi.org/10.5194/egusphere-egu21-5609

EGU General Assembly 2021

(c) Author(s) 2021. This work is distributed under

the Creative Commons Attribution 4.0 License.

\section{How are guaranties of quality forged and assessed in flood risk modelling?}

Remi Barbier and Isabelle Charpentier

ENGEES, France (remi.barbier@engees.unistra.fr)

Models and simulations have become essential elements of water management in catchments (Chong, 2019). This raises the question of confidence in the models. We are interested in the criteria used to judge their quality and the way in which the uncertainties inherent to modelling are taken into account and explained throughout the process.

Our communication is based on the results of one interdisciplinary research project on modelling developed in the framework of Flood Risk Prevention Plans (FRPP). In a nutshell, FRPPs are regulatory documents elaborated under the responsibility of the State. They are then imposed to local urban planning regulations. Their elaboration is based on the modelling of the flood hazard.

We formulate the problem of trust from the perspective of the State services. The latter entrust consulting firms with the implementation of hazard modeling, which (generally) benefit from a strong asymmetry of skills in their favour. Based on a survey conducted in several government departments, we analyze the practice of ordering, piloting and validating these models. The question posed is the following: "how are guaranties of quality and suitability forged and assessed in flood risk modelling?" We review the different stages of the process, from the writting of the specifications to the final validation of the results, including the multiple interactions throughout the work. 